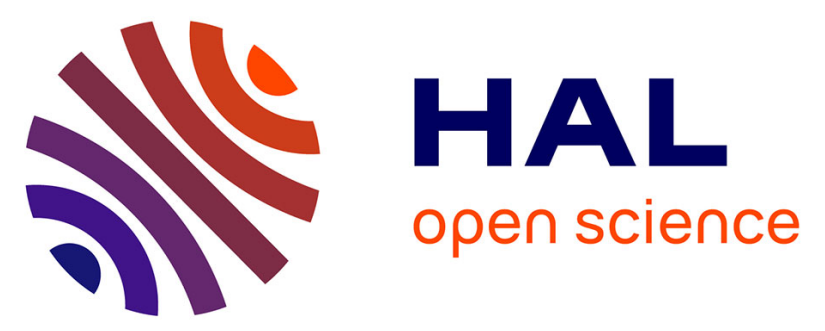

\title{
Advantages of the Analytic Element Method for the Solution of Groundwater Management Problems
}

\author{
Shishir Gaur, Djamel Mimoun, Didier Graillot
}

\section{To cite this version:}

Shishir Gaur, Djamel Mimoun, Didier Graillot. Advantages of the Analytic Element Method for the Solution of Groundwater Management Problems. Hydrological Processes, 2011, 10.1002/hyp.8071 . emse-00579967

\section{HAL Id: emse-00579967 https://hal-emse.ccsd.cnrs.fr/emse-00579967}

Submitted on 26 Nov 2021

HAL is a multi-disciplinary open access archive for the deposit and dissemination of scientific research documents, whether they are published or not. The documents may come from teaching and research institutions in France or abroad, or from public or private research centers.
L'archive ouverte pluridisciplinaire HAL, est destinée au dépôt et à la diffusion de documents scientifiques de niveau recherche, publiés ou non, émanant des établissements d'enseignement et de recherche français ou étrangers, des laboratoires publics ou privés.

\section{다)(1) $(5$}

Distributed under a Creative Commons Attribution - NonCommerciall 4.0 International 


\title{
Advantages of the analytic element method for the solution of groundwater management problems
}

\author{
Shishir Gaur,* Djamel Mimoun and Didier Graillot \\ SITE, Ecole Nationale Supérieure des Mines de Saint-Etienne, Saint Etienne, France
}

\begin{abstract}
In the simulation-optimization approach, a coupled optimization and groundwater flow/transport model is used to solve groundwater management problems. The efficiency of the numerical method, which is used to simulate the groundwater flow, is one the major reason to obtain the best solution for a management problem. This study was carried out to examine the advantages of the analytic element method (AEM) in the simulation-optimization approach, for the solution of groundwater management problems. For this study, the AEM and finite difference method (FDM) based flow models were developed and coupled with the particle swarm optimization (PSO)-based optimization model. Furthermore, the AEM-PSO and FDM-PSO models developed were applied in hypothetical as well as real field conditions to address groundwater management problems and the results were compared. For the real field situation, the models developed were applied to the Dore River basin in France to minimize the installation and operational cost of new pumping wells taking the location and discharge of the pumping wells as decision variables. The constraints of the problem were identified with the help of stakeholders and water authority officials. The AEM flow model was developed to facilitate the management model particularly when at each iteration, the optimization model calls for a simulation model to calculate the values of groundwater heads. The results show that, at some points, the AEM-PSO model is efficient in identifying the optimal location of wells and consequently results in optimal costs, sometimes difficult when using the FDM.
\end{abstract}

KEY WORDS groundwater modelling; groundwater management; analytic element method; finite difference method; particle swarm optimization

\section{INTRODUCTION}

Groundwater management problems are typically solved by researchers using the simulation-optimization approach. In the simulation-optimization approach, a coupled optimization and groundwater flow/transport model is used to establish the best management practices to address the groundwater management problems in question. During the past two decades, several computer codes have been developed to address groundwater management problems by linked groundwater flow/transport and optimization models (Shamir et al., 1984; Ahlfeld et al., 1986; Lefkoff and Gorelick, 1986; Willis and Finney, 1988; Finney and Samsuhadi, 1992; Emch and Yeh, 1998; Zheng and Wang, 2002). These codes differ in the numerical model used to represent the groundwater flow system or contamination transport system, the type of groundwater management problems and the approaches used to solve these management problems (Ahlfeld et al., 2005). Extensive literature reviews have been made on this topic by different researchers (Gorelick, 1983; Willis and Yeh, 1987; Das and Datta, 2001; Qin et al., 2009). These reviews show that in all previous groundwater management studies, the finite difference method (FDM)or finite element method (FEM)-based flow model was

* Correspondence to: Shishir Gaur, SITE, Ecole Nationale Supérieure des Mines de Saint-Etienne, Saint Etienne, France.

E-mail: s.gaur@yahoo.com used, and are thus affected by the limitation of these methods such as domain discretization error, selection of appropriate boundary conditions, numerical stability, and approximate location of well over the cell.

The analytic element method (AEM) is a computational method based on the superposition of analytical expressions to represent two-dimensional (2D) vector fields. Analytic element models can superimpose hundreds of exact analytic solutions to solve groundwater flow problems and are capable of simulating streams, lakes, and complex boundary conditions (Strack, 1989). The AEM is a grid independent method and has certain advantages over grid-based methods. A few researchers have made some comparison studies on the AEM with grid based methods such as FDM, but not in the context of optimization problems. They found that AEM presents some advantages compared with grid-based methods or to facilitate complex FDM- or FEM-based models. Hunt et al. (1998) performed a study to analyze the benefits of an AEM model as a screening tool that can improve the calibration of more complicated FDM and FEM models. The AEM was used to remove the error in an FDM model due to incorrect specification of boundary conditions. They found that the AEM has the potential of being a powerful screening model that can help achieve better calibration of complicated FDM and FEM models. Olsthoorn (1999) performed comparative analysis of AEM- and FDM-based models. Both the AEM- and 
FDM-based models were developed for the area used for the Amsterdam city water supplies. The study concluded that the AEM model was more efficient than the FDM model, on some conditions. With the AEM, wells are directly represented by their exact co-ordinates (Matott et al., 2006). Also, the AEM flow solutions are inherently continuous over the domain and give a more accurate water budget for the area. In the AEM model, the computational effort depends on the number of features and their discretization level, not on the spatial extent of the domain, thus making it possible to model the main features of large geographic areas at high resolution without excessive computation time (Bandilla et al., 2007). Although these types of limitation in the FDM/FEM based solutions can be overcome by spatial grid adaptation methods, such methods give rise to a more complicated linkage between the simulation-optimization model and the computational burden (Matott et al., 2006).

Groundwater management models are often characterized as nonconvex, nonlinear programming problems (Willis and Yeh, 1987). Most of the traditional optimization techniques are gradient based and the solutions from these methods produce local optimal values rather than a global optimal solution. Consequently, the application of gradient-based optimization techniques may be difficult in real-life problems related to well optimization. On the other hand, global search methods are efficient in finding a global solution to the problem. Constraints in global optimization methods can be incorporated into the formulation and do not require derivatives with respect to decision variables as in nonlinear programming (McKinney and Lin, 1994). In recent years, applications of global search methods have grown in number and these methods have been applied to solve different kinds of groundwater quantity and quality management problems. Genetic algorithms were applied by Wang and Zheng (1998), Goldberg (1989), Wang (1991), Rogers and Dowla (1992), and McKinney and Lin (1993, 1994). Simulated annealing (SA) was applied by Dougherty and Marryott (1991) and Marryott et al. (1993). Ritzel et al. (1994), Cieniawski et al. (1995), and Johnson and Rogers (1995) used global search methods in their studies and found that these methods were more efficient and robust in comparison with other methods such as linear, nonlinear, and mixed integers. McKinney and Lin (1994) developed the genetic algorithm (GA)-based groundwater simulationoptimization models to solve three groundwater management problems. They found that genetic algorithms could effectively and efficiently be used to obtain globally (or, at least near globally) optimal solutions to these groundwater management problems. Particle swarm optimization (PSO), which is also an evolutionary computation technique, was developed by Kennedy and Eberhart (1995). It has been applied in various fields of engineering research and has proved to be an effective and efficient method. Limited application of PSO has been found suitable in the field of water resources and particularly groundwater management. Wegley et al. (2000) used PSO for optimizing pump operations in water distribution systems. The objective of their study was to minimize energy costs, while maintaining pressure heads and tank levels within acceptable bounds. Finally, pump speeds for variable frequency drive pumps were proposed. The study suggested that PSO converged to global optimal solutions and gave good results. Matott et al. (2006) solved pump and treatment optimization problems using the AEM-based flow model. The AEM model was coupled with the optimization model and results were generated with different optimization techniques, i.e. GA, SA, conjugate gradient (CG), and PSO were compared. The PSO was found to produce good results in comparison with other methods.

This study describes the benefits of using the AEM model in the simulation-optimization approach. In the study, the AEM- and FDM-based flow models were coupled with the PSO-based optimization model. The comparative analysis was performed between AEM and FDM, and the abilities of the AEM method to solve groundwater management problems were investigated. The influence of both methods on piping cost, the controlling parameter in identifying the location of wells, was examined.

\section{FORMULATION OF THE SIMULATION-OPTIMIZATION MODEL}

In the study, AEM- and FDM-based flow models were developed. A PSO-based optimization model was also developed and validated with standard functions. After development and validation of simulation and optimization models, both models were coupled to solve groundwater management problems. The coupled AEMPSO code was developed particularly to facilitate the simulation-optimization approach, in which the optimization model repeatedly calls on the simulation model. The FDM model was also coupled with the PSO model. In addition, coupled AEM-PSO- and FDM-PSO-based simulation-optimization models were used to establish the maximum discharge from the aquifer and minimum pumping cost for wells, considering well discharge and well location as decision variables. The piping cost was also considered in the objective function and its effect on the final solution was examined.

\section{AEM flow model}

In the AEM model, groundwater flow is often expressed in terms of complex potential $\Omega\left(\mathrm{m}^{3} / \mathrm{s}\right)$ as

$$
\Omega=\Phi+i \Psi
$$

where discharge potential $\Phi\left(\mathrm{m}^{3} / \mathrm{s}\right)$ and the stream function $\Psi\left(\mathrm{m}^{3} / \mathrm{s}\right)$ fulfil the Cauchy-Riemann condition, therefore, $\Phi$ and $\Psi$ may be represented as real and imaginary parts of an analytical function $\Omega=\Omega(z)$ of the complex variable $z=x+i y$, defined in the flow domain. As the AEM is based on potential theory, the discharge potential $\Phi(x, y)$ for a given aquifer is determined by 
superimposing the contribution from individual elements that correspond to particular hydraulic features (e.g. river, lakes, pumping wells, and zones of different hydraulic conductivity). Finally the potential is converted into head $\phi(\mathrm{m})$ by the following relation:

$$
\Phi=\frac{1}{2} k \phi^{2}
$$

for an unconfined aquifer and

$$
\Phi=k H \phi-\frac{1}{2} k H_{\mathrm{a}}^{2}
$$

for a confined aquifer, where $H_{\mathrm{a}}$ is the aquifer thickness (m) and $k$ the hydraulic conductivity $(\mathrm{m} / \mathrm{s})$. The solution of this equation is achieved by defining boundary conditions along the border of the hydrogeological element, instead of defining the boundary condition along the model domain boundary. The detailed description of analytic element functions for different hydrogeological features can be found in Strack (1989). In this study, the AEM model was developed following the above methodology on the MATLAB 7.0 platform.

\section{Finite difference method}

The governing groundwater flow equation for a $2 \mathrm{D}$ unconfined aquifer can be given as

$$
\begin{gathered}
\frac{\partial}{\partial x}\left(K_{x} \frac{\partial h}{\partial x}\right)+\frac{\partial}{\partial y}\left(K_{y} \frac{\partial h}{\partial y}\right)+\frac{\partial}{\partial z} \\
\left(K_{z} \frac{\partial h}{\partial z}\right)-W=S_{\mathrm{s}} \frac{\partial h}{\partial t}
\end{gathered}
$$

Equation (4) is a differential equation that can be used to predict the spatial and temporal variability of groundwater head $(h)$ in an aquifer system. $W$ is a flux term that incorporates pumping, recharge, or other sources or sinks. Equation (4) can be solved with a finite difference solution by discretizing the domain in a $2 \mathrm{D}$ grid. The solution of the finite difference equation gives the average value of $h$ for each grid cell. In this study, the 2D steady state groundwater flow model was developed on the MATLAB platform.

\section{Particle swarm optimization}

PSO is an efficient method for solving large nonlinear, complex global optimization problems and, in some cases, it performs more efficiently in comparison with other evolutionary computation techniques (Eberhart and Kennedy, 1995). PSO is one of the many swarm intelligence-based methods that are suitable for solving global optimization problems. PSO is an evolutionary computation technique, based on the simulation of simplified social models, such as bird flocking, fish schooling, and the swarm theory (Kennedy et al., 2001). Put simply, it can be compared to birds searching for food, which consider two factors to achieve their goal: their own previous best experience (i.e. pbest) and the best experience of all other members (i.e. gbest). This is also similar to human behaviour in decision making when people consider their own best past experience and the best experience of other people around them (Jarboui et al., 2008).

The working steps of the PSO method for the solution of any optimization problem are as follows:

1. Initialize a population (array) of particles with random positions and velocities for the dimensions in the problem space. The decision variables in the PSO are represented by the dimensions of each particle.

2. Determine the fitness value of each particle by a fitness function.

3. Compare each particle's fitness evaluation with the particle's pbest. If the current value is better than pbest, then set the pbest value as equal to the current value and the pbest location equal to the current location in $d$-dimensional space.

4. Compare the fitness evaluation with the population's overall previous best. If the current value is better than gbest, then reset gbest to the current particle's array index and value.

5. Change the velocity and position of the particle according to Equations (5) and (6) given below,

$$
\begin{aligned}
& v_{i j}^{t}=\chi\left[\omega v_{i j}^{t-1}+c_{1} r_{1}\left(P_{i j}^{t-1}-x_{i j}^{t-1}\right)+c_{2} r_{2}\left(G_{j}^{t-1}-x_{i j}^{t-1}\right)\right] \\
& x_{i j}^{t}=x_{i j}^{t-1}+v_{i j}^{t}
\end{aligned}
$$

where $i$ and $j=1,2, \ldots, N, N$ is the total number of swarm, $c_{1}$ and $c_{2}$ are acceleration constants, $r_{1}$ and $r_{2}$ are random real numbers between 0 to 1 . Thus, the particle flies through potential solutions toward $P^{t}$ and $G^{t}$ in a navigated way while still exploring new areas by the stochastic mechanism to escape from local optima. $\omega$ is called inertia weight which is used to control the impact of the previous history of velocities on the current one. $\chi$ is the constriction coefficient, used to restrain velocity. 6. Loop to step 2 until a criterion is satisfied, usually a sufficiently good fitness or a maximum number of iterations (generations).

Since there is no actual mechanism for controlling the velocity of a particle, it is necessary to impose a maximum value $V_{\max }$, which controls the maximum travel distance in each iteration to avoid the particle flying past good solutions. Also, after updating the positions, it must be checked that no particle violates the boundaries of the search space. If a particle has violated the boundaries, it will be set at the boundary of the search space. The PSO model was developed on the MATLAB platform following the above mentioned methodology.

\section{OBJECTIVE FUNCTION}

Mathematically, a typical groundwater management problem can be defined using three main components, i.e. decision variables, objective function, and constraints 
(Ahlfeld et al., 2005). In this study, two objectives, maximum groundwater extraction rate for pumping wells and minimum pumping cost for wells, have been achieved.

\section{Maximizing the discharge}

In this case, the objective function is to determine the maximum amount of water which can be withdrawn from the aquifer through a given number of wells (Ayvaz, 2009). Therefore,

$$
f=\operatorname{Max}\left\{\sum_{i=1}^{N_{\mathrm{w}}} Q_{i}-\beta P(h)\right\}
$$

subject to

$$
\begin{aligned}
& Q_{i, \text { min }}<Q_{i}<Q_{i, \text { max }} \\
& h_{i}>h_{i, \text { min }}
\end{aligned}
$$

whereas penalty function is defined as

$$
P(h)=\left\{\begin{array}{lll}
h_{i, \text { min }}-h_{i} & \text { if } & h_{i}<h_{i, \text { min }} \\
0 & \text { if } & h_{i} \geq h_{i, \text { min }}
\end{array}\right.
$$

where $Q_{i, \min }$ and $Q_{i, \max }\left(\mathrm{m}^{3} / \mathrm{s}\right)$ are the minimum and maximum discharge limits for $i$ th well. $i=1,2, \ldots, N_{\mathrm{w}}$, $N_{\mathrm{w}}$ is the total number of wells, $\beta$ is the weighting factor, selected according to the problem.

\section{Minimizing the cost}

The total cost for a new system of pumping wells consists of the cost of well installation, piping cost, pump cost and cost of pumping (operating cost). The well cost includes the cost of drilling, casing, well screen, filter pack, sealing, and well development. In the study, well cost was taken as a constant term, as all wells were taken to be of the same depth and diameter. Well installation cost was not included in the optimization function but was considered when establishing the total cost of the system to identify the influence of it for calculating the optimal number of wells.

The piping cost depends on the location of the new wells along with many other factors. In this study, the piping length considered was the distance from wells to a reference location. The reference location consisted of a water storage tank where water from all the wells will be stored and subsequently transported to the city. All the pipes were taken to be of the same diameter and material. The pump operating cost depends on the volume of water to be pumped, weight density of the water, hydraulic head, efficiency of the pump, and energy cost (Moradi et al., 2003; Sharma and Swamee, 2006).

Therefore, the objective function consists of the cost of piping, cost of pump units, and the operating cost including the annual repair and maintenance cost (Swamee and Sharma, 1990; Swamee, 1996). So the objective is defined as follows:

$$
\begin{aligned}
C_{\mathrm{p}}= & \operatorname{Min}\left\{\sum_{i=1}^{N_{\mathrm{w}}}\left(A_{2} L_{i}+k_{\mathrm{P}} \frac{\gamma Q_{i} H_{i}}{\eta}+\frac{8 \cdot 76 R_{\mathrm{E}} \gamma Q_{i} H_{i} r_{\mathrm{T}}}{\eta}\right)\right. \\
& \left.+\beta_{1} P(h)+\beta_{2} P(Q)\right\}
\end{aligned}
$$

subject to

$$
\begin{aligned}
& Q_{i, \text { min }}<Q_{i}<Q_{i, \text { max }} \\
& \sum_{i=1}^{N} Q_{i}>Q_{\text {total }} \\
& h_{i}>h_{i, \text { min }}
\end{aligned}
$$

whereas penalty function is define as,

$$
\begin{gathered}
P(h)=\left\{\begin{array}{lll}
h_{i, \min }-h_{i} & \text { if } & h_{i}<h_{i, \min } \\
0 & \text { if } & h_{i} \geq h_{i, \min }
\end{array}\right. \\
P(Q)=\left\{\begin{array}{lll}
Q_{\mathrm{tot}}-\sum Q_{i} & \text { if } & \sum Q_{i}<Q_{\mathrm{tot}} \\
0 & \text { if } & \sum Q_{i} \geq Q_{\mathrm{tot}}
\end{array}\right.
\end{gathered}
$$

$r_{T}=1 / r$ where $r_{T}=\frac{(1+r)^{T}-1}{r(1+r)^{T}}, r$ is the rate of interest expressed as c/c/year, $T$ is the life of project (in years) and duration of the project (i.e. $T \rightarrow \infty$ ), $k_{P}$ is the cost of a pump per unit kwh (c), which can be obtained by interpolating values from a curve between cost and pump capacity. The pump parameters were established on the basis of market surveys of branded pumps of various heads and capacities.

\section{MODEL APPLICATION}

Both AEM-PSO and FDM-PSO models were applied to a hypothetical problem given by McKinney and Lin (1994) and real field data for the Dore River basin, France.

\section{Hypothetical problem}

This typical sample problem was also solved by various researchers (Wang and Zheng, 1998; Ayvaz, 2009) using different optimization methods, i.e. linear programming, genetic algorithm, simulation annealing, and harmony search. The hypothetical problem concerns identification of the maximum discharge from 10 pumping wells in a homogeneous, isotropic, and unconfined aquifer. This hypothetical case consists of no-flow boundaries on two sides and constant head boundaries on the other two sides. Hydraulic conductivity $=50 \mathrm{~m} /$ day, areal recharge $=0.001 \mathrm{~m} / \mathrm{day}$, and constant head $=20 \mathrm{~m}$ on both bound aries were adopted. The objective function for this problem was taken as for Equation (7). Two constraints were considered in the problem, (1) hydraulic head should be above the aquifer bottom and (2) discharge range of the pumping wells should be within the limits of $0-7000 \mathrm{~m}^{3} /$ day.

In the existing studies, FDM- and FEM-based flow models were used. In this study, an AEM-based flow model was used in which constant head boundaries were represented by line-sink elements and no-flow boundaries by thin homogeneity lines, with very low conductivity of $1 \times 10^{-10} \mathrm{~m} /$ day. A total of 25 particles were used with the dimension of 10 where each dimension represented the discharge value for one well. The values for different parameters of the PSO model were established on a 
Table I. Maximum discharge by 10 pumping wells using different optimization techniques

\begin{tabular}{lrrrrrr}
\hline Well no. & \multicolumn{6}{c}{ Optimization techniques } \\
\cline { 2 - 7 } & LP & GA & SA & HS & $\begin{array}{r}\text { FDM- } \\
\text { PSO }\end{array}$ & $\begin{array}{c}\text { AEM- } \\
\text { PSO }\end{array}$ \\
& & & & & & \\
\hline 1 & 7000 & 7000 & 7000 & 7000 & 7000 & 7000 \\
2 & 7000 & 7000 & 7000 & 7000 & 7000 & 7000 \\
3 & 7000 & 7000 & 7000 & 7000 & 7000 & 7000 \\
4 & 6000 & 5000 & 6200 & 5904 & 6300 & 6315 \\
5 & 4500 & 5000 & 4700 & 4590 & 4600 & 4600 \\
6 & 6000 & 6000 & 6200 & 5904 & 6150 & 6150 \\
7 & 6800 & 7000 & 6650 & 6821 & 6500 & 6600 \\
8 & 4100 & 4000 & 4000 & 4121 & 4100 & 4055 \\
9 & 4100 & 4000 & 4000 & 4120 & 4100 & 4100 \\
10 & 6800 & 7000 & 6650 & 6820 & 6600 & 6605 \\
Total & 59300 & 59000 & 59400 & 59279 & 59350 & 59425 \\
\hline
\end{tabular}

trial and error basis. Finally, the value for linearly varying inertia weight was taken as $0.9-0.4$, whereas the acceleration constants, i.e. $c_{1}$ and $c_{2}$, were defined as 2 . The termination criterion was defined on the basis of a maximum number of iterations, i.e. 200. After applying the model to the problem, it was found that the AEM-PSO solution converged to the optimal value of 59 $425 \mathrm{~m}^{3} /$ day after 97 iterations. The results generated by the AEM-PSO and FDM-PSO models were compared with the results generated by other methods. Table I shows the maximum discharge by 10 pumping wells using different optimization techniques. Figure 1 shows the representation of the hypothetical case with AEM and the groundwater head contours generated by the AEM-PSO model for the maximum pumping values. The results demonstrate that the AEM-PSO model is more efficient in comparison with linear programming and genetic algorithm. The AEM-PSO model gives a higher value for cost function in comparison with other methods and it also converges faster than the GA method. It can also be observed that FDM-PSO performed slightly better in comparison with other methods. The FDMPSO solution was seen to converge to the optimal value of $59350 \mathrm{~m}^{3} /$ day after 74 iterations. This exercise produced two main conclusions: (1) the PSO model converges faster and performs well in comparison with other methods and (2) the AEM method is capable of producing a higher value for the optimal solution in comparison with other methods. It was also found that the AEM-PSO model takes more iterations to converge, in comparison with FDM-PSO and SA.

\section{Real field application}

After the application of the AEM-PSO and FDM-PSO models to the hypothetical problem, they were applied to the water requirements of the town of Thiers, which is one of the major towns in the Loire region, France. The models developed were applied to minimize the pumping

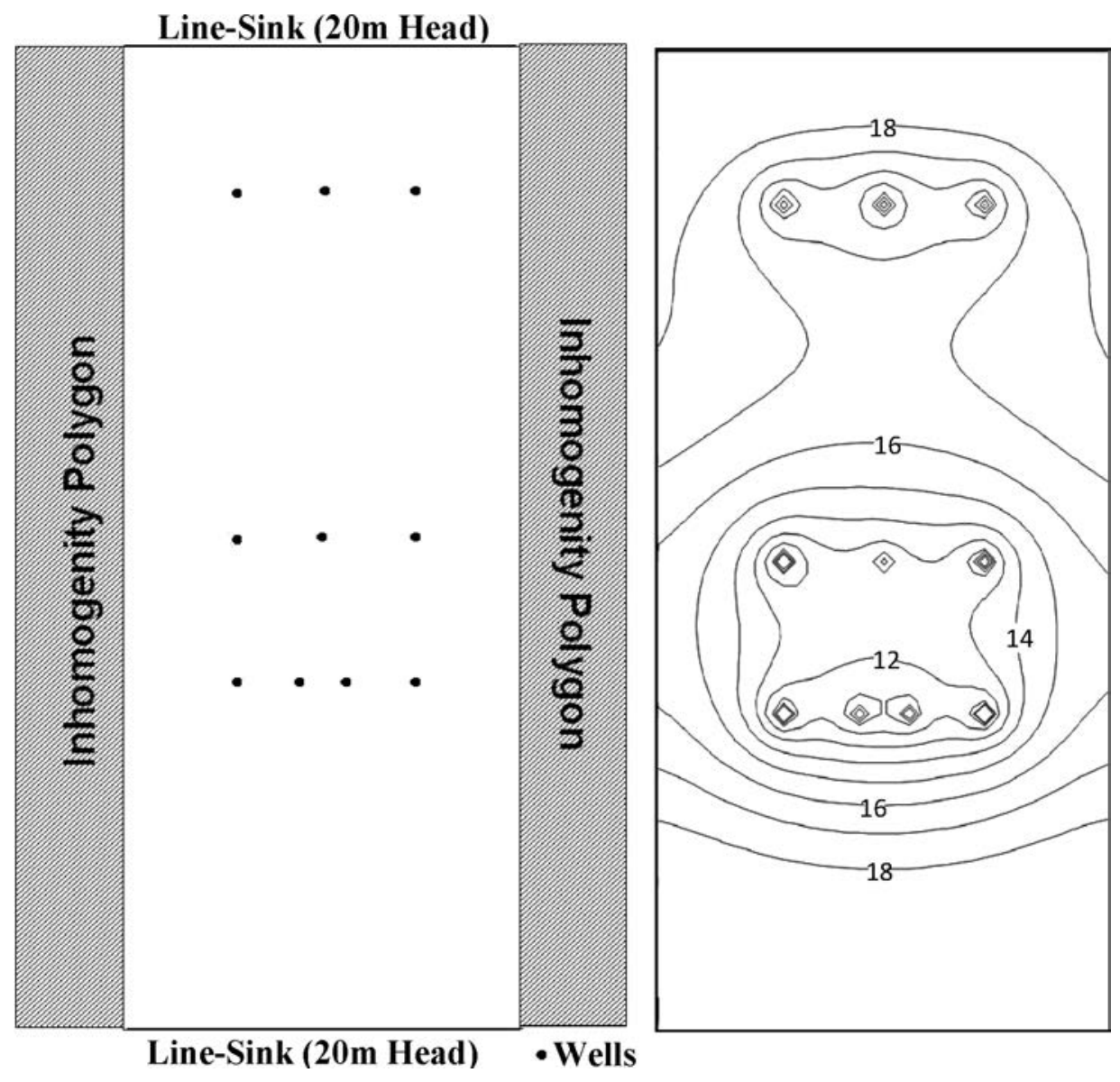

Figure 1. Hypothetical case: plan view in AEM and groundwater head calculated by AEM-PSO model 
cost by identifying the optimal location and discharge of wells and satisfying the specific constraints of the situation. The inhabitants of Thiers total 20000 and the population in the local region is 23500 . The Dore River catchment, which is situated in the eastern part of the Massif-Central in France (Figure 2), was examined to establish the new pumping wells. The study area consists of two rivers, i.e. Allier and Dore, where the Dore River is an important tributary of the Allier River.

The study area lies between $45^{\circ} 54^{\prime} \mathrm{N}$ to $46^{\circ} \mathrm{N}$ latitude and $3^{\circ} 25^{\prime} \mathrm{E}$ to $3^{\circ} 29^{\prime} 10^{\prime \prime} \mathrm{E}$ longitude. The low flow period in the river occurs in summer, i.e. June-August but can extend up to November. The major part of the area is covered by fluvial quaternary sediments underlain by marl and clay. The quaternary alluvium is composed of gravel, sand, and pebbles with silt. The impervious substratum is composed of clay and sand (Oligocene period). The hydraulic conductivity in the domain varies from $1 \times 10^{-3}$ to $3 \times 10^{-3} \mathrm{~m} / \mathrm{s}$, whereas the thickness of the aquifer varies from 12 to $15 \mathrm{~m}$. The elevation of the bottom impervious layer of aquifer varies from 254 to $258 \mathrm{~m}$ from mean sea level (MSL). The location of different hydrological features and other required data were extracted from the geological maps provided by the BRGM (Bureau de Recherches Géologiques et Minières). A total of 12 piezometric measurements are available in the study area (Figure 2), which show the hydraulic gradient in the North direction.

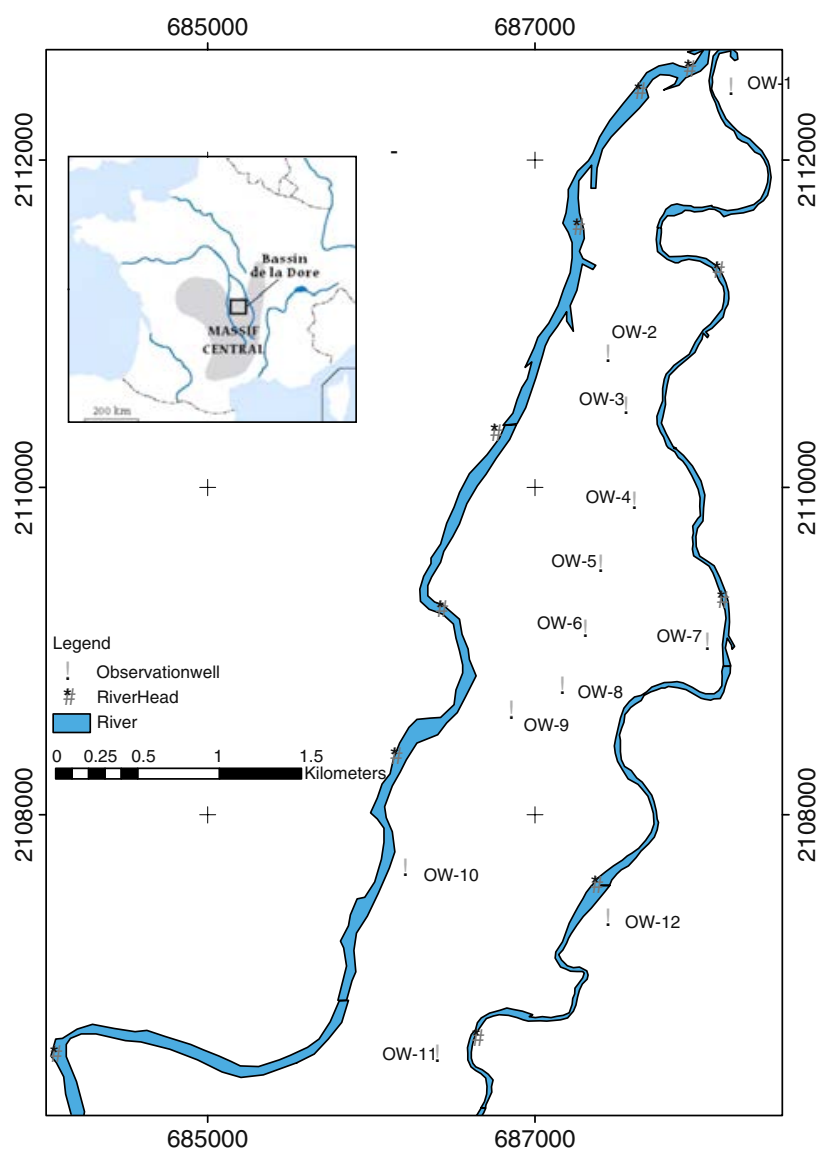

Figure 2. Location of the study area

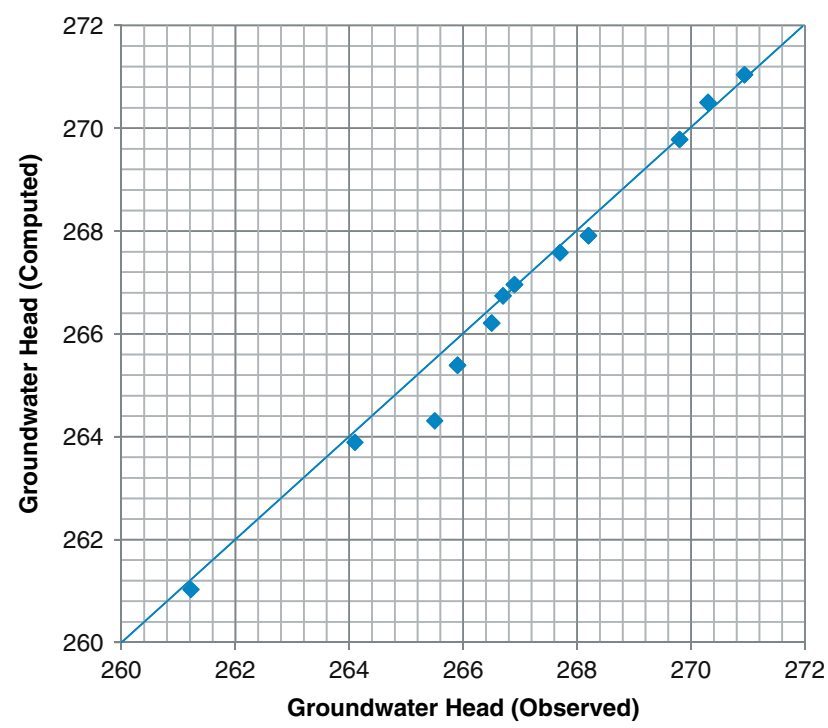

Figure 3. Model calibration graph between computed and observed groundwater head values

In the AEM model, the rivers considered in the study area were represented by 39 head line-sink elements. The water level in the river is monitored at 11 different locations and was used to define the boundary condition for line-sink elements. The discharge wells were represented by well elements. The model was developed with the given line-sinks and wells with constant hydraulic conductivity in the whole domain. In the model, a constant elevation for the bottom layer was taken: $257 \mathrm{~m}$. The model was run in the steady-state condition for the low flow period, i.e. June 2007. This period was found to be suitable for the steady-state model run as the river condition was found to be almost stable along with a static groundwater head. The computed heads were compared with observed heads at 12 different locations in the domain to calibrate the model with real field conditions. In the calibration process, a hydraulic conductivity value was adjusted systematically and the model output was compared with observed values. The results of the model showed that changing the hydraulic conductivity values by up to $25 \%$ did not affect the groundwater head more than $1 \mathrm{~m}$. In addition, in the calibration process, part of the river outside the area of interest was included and its effect on groundwater head was examined. This process helps establish the effect of far field features on the area of interest. The model was not found to be very sensitive for the far features as the area of interest is located between the two neighbouring rivers. Figure 3 shows the graph between observed and computed groundwater head. Once the model parameters had been calibrated from the AEM model, the same parameters were used to develop the FDM model. The FDM model grid size was taken as $25 \times 25 \mathrm{~m}$. A calibration graph was also developed for the FDM model and found to be consistent, as in the case of the AEM model. Figure 4 shows the groundwater head generated by the AEM as well as the FDM model and was found to be consistent. 


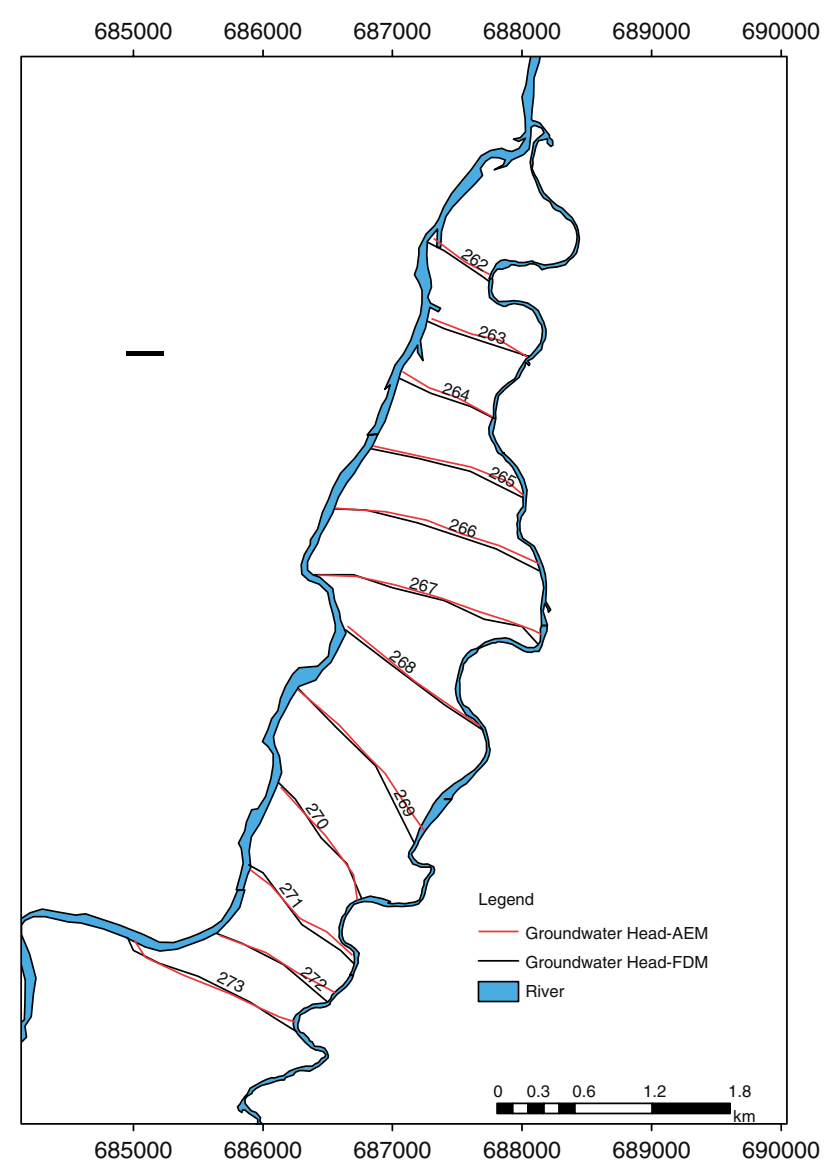

Figure 4. Groundwater contours generated by AEM and FDM models

In addition, the AEM-PSO and FDM-PSO models were applied to the Dore River basin to minimize the well pumping cost (Equation (14)). In the cost function, values of different parameters were defined: $A_{1}$ was taken as 4000 euros which includes steel casing and 12-m well depth. Based on the experience of the field experts, $A_{2}$ was taken as 140 euros/m. A market survey was carried out to collect the information for available pumps. Due to the availability of pumps for the specific capacity, the pump power for each well was computed and a pump with the same or higher capacity was obtained. The values of other parameters were selected as follows: $R_{\mathrm{E}}=0.08$ euros per kwh; $\gamma=9810 \mathrm{~N} / \mathrm{m}^{3} ; \eta=80 \%$, $r=6 \%$ euros/year and $T=25$ years. The co-ordinates of the reference location were defined as $X=687000$ and $Y=218000$, which used to compute the piping length. The overall cost for the system and the optimal number of wells was determined by Equation (15), where the optimal pumping cost (Equation (9)) and well installation cost (Equation (8)) were added.

A total of four constraints were defined in the problem. The constraints of the problem were identified with the discussion of stakeholders and water authority officials. A questioner was prepared and filled by stake holders and officials to identify the maximum discharge limit and permissible drawdown limit. The first constraint was established to limit the drawdown of groundwater under the permissible limit. Since the average saturated thickness of the aquifer was about $10 \mathrm{~m}$, the permissible limit of drawdown was defined as $261 \mathrm{~m}$, while the average level of the aquifer bottom was taken as $257 \mathrm{~m}$. The second constraint was fixed to assure the minimum water demand of the area. Per capita water consumption was considered as $160 \mathrm{l} /$ day/person, which is the standard value for water consumption in France. Thus, the total pumping rate for all the wells was defined as equal to or greater than $820 \mathrm{~m}^{3} / \mathrm{h}$. The third constraint was used to define the maximum and minimum discharge limit for a single well. On the basis of aquifer properties and availability of pumps, the discharge limit was set at $100 \mathrm{~m}^{3} / \mathrm{h}<Q_{i}<280 \mathrm{~m}^{3} / \mathrm{h}$. The fourth constraint incorporated the minimum distance between the wells. Taking local practices into consideration and to ensure a protective zone around the wells, a minimum distance between any two wells was set at $150 \mathrm{~m}$.

The models were run for different sets of wells and an overall system cost for the given set of wells was computed. Sets of four, five, and six wells were considered in the problem. Finally, the results from different sets of wells were compared and the optimal number of wells was determined. The parameters of the PSO model were taken in similar fashion to the earlier case. The results of the AEM and FDM models were compared on two aspects, i.e. piping length and drawdown. Figure 5 shows the location of optimal wells as established by the AEM and FDM models. The figure shows that the optimal piping length differs in the AEM and FDM models. As the AEM gives the exact location of the wells, it calculated the exact length of pipe, i.e. $1053 \mathrm{~m}$, whereas the piping length calculated by the FDM model was $1157.2 \mathrm{~m}$. The results show that the piping cost established by the AEM-PSO model is $9 \%$ less than that with the FDM-PSO model.

To compare the effect of both models on drawdown, the FDM model was developed with two grid sizes, i.e. $50 \times 50$ and $25 \times 25 \mathrm{~m}$. Table II shows the drawdown according to the AEM and FDM models, it also shows that the AEM model gives a more accurate drawdown which helps establish a more accurate cost for pumping. Although with FDM, the accuracy in measuring the head can be achieved by reducing the cell size but the computational burden can be increased excessively with larger domains. The optimal cost for pumping according to the AEM model is 97640 euros, whereas with the FDM model, it is 96341 euros with grid size $25 \times 25 \mathrm{~m}$ and 94613 euros with grid size $50 \times 50 \mathrm{~m}$. The results show that the FDM model with grid size $25 \times 25$ decreases the pumping cost by $1.33 \%$, whereas the $50 \times 50$ grid size decreases the cost by $3.1 \%$. The results conclude that in the simulation-optimization approach, the minimum value of objective function, in cost minimization, is not always an accurate value. If grid-based methods are used in a simulation-optimization approach, grid size is an important influencing parameter in identifying the exact value of groundwater head and as a consequence, the exact value of cost function. Figure 6 shows the graph plotted between overall cost of the 

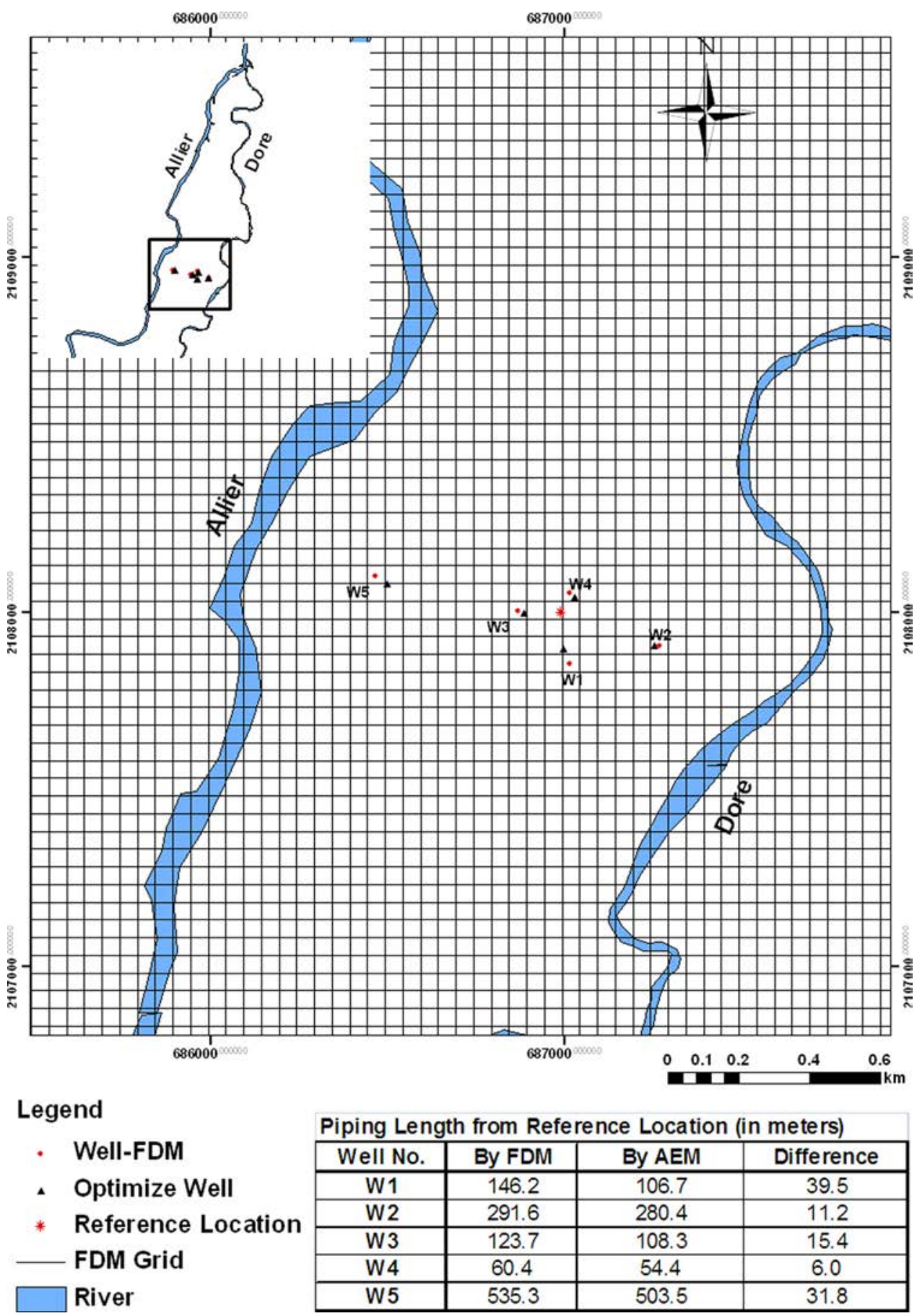

Piping Length from Reference Location (in meters)
\begin{tabular}{|c|c|c|c|}
\hline WeIl No. & By FDM & By AEM & Difference \\
\hline W1 & 146.2 & 106.7 & 39.5 \\
\hline W2 & 291.6 & 280.4 & 11.2 \\
\hline W3 & 123.7 & 108.3 & 15.4 \\
\hline W4 & 60.4 & 54.4 & 6.0 \\
\hline W5 & 535.3 & 503.5 & 31.8 \\
\hline
\end{tabular}

Figure 5. Optimal locations of wells calculated by AEM and FDM model

Table II. Drawdown by AEM and FDM model

\begin{tabular}{lccc}
\hline Well no. & By FDM $(50 \times 50)$ & By FDM $(25 \times 25)$ & By AEM \\
\hline W1 & 264.7 & 264.2 & 263.9 \\
W2 & 264.6 & 263.8 & 263.6 \\
W3 & 264.7 & 264.2 & 264 \\
W4 & 264.5 & 264.1 & 263.8 \\
W5 & 264.9 & 264.0 & 263.7 \\
\hline
\end{tabular}

system and different sets of wells. In this context, the set of five wells was found to be optimal.

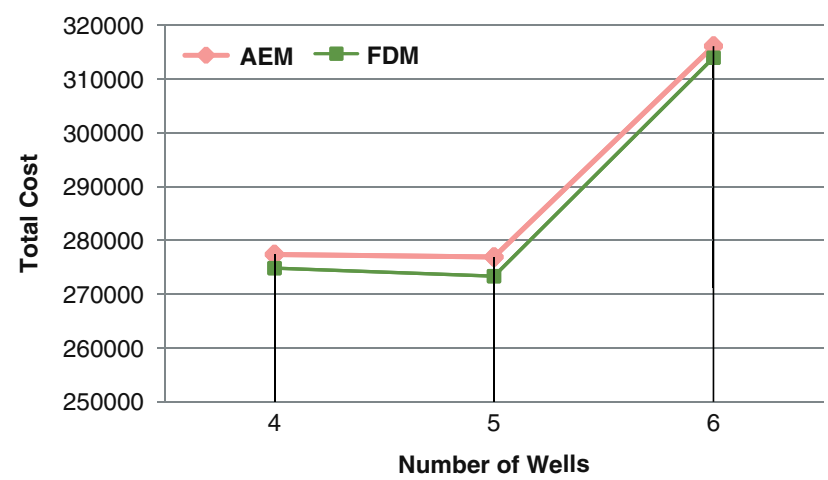

Figure 6. Optimal cost calculated by AEM-PSO and FDM-PSO model for the set of five wells 

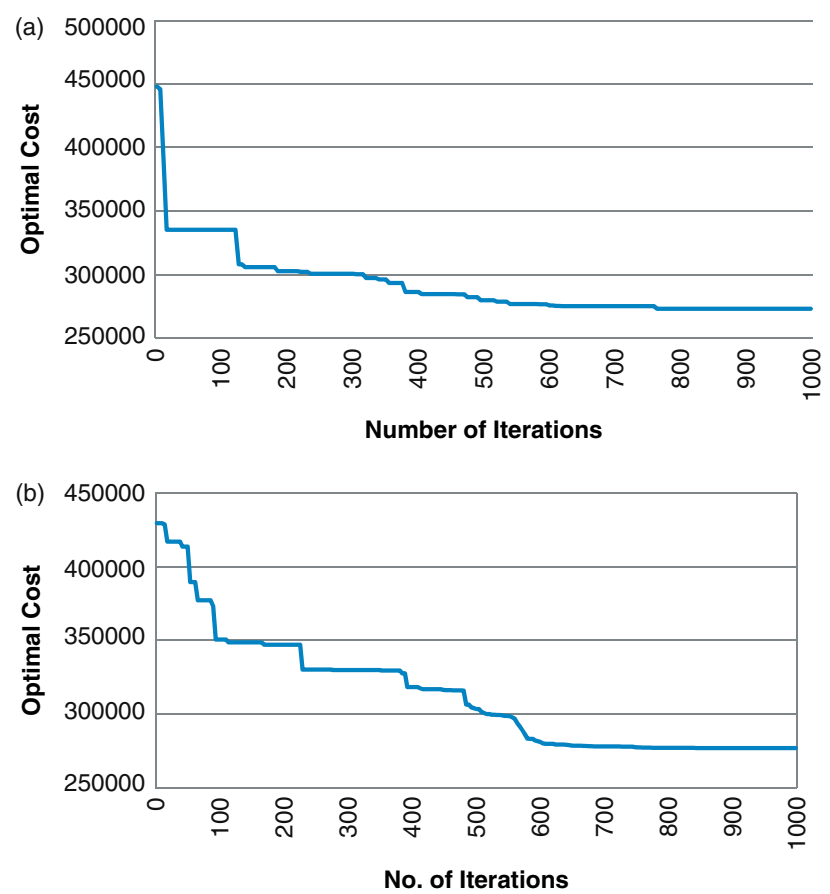

Figure 7. Convergence graph for real field case study by (a) FDM-PSO and (b) AEM-PSO

Convergence of the optimization model was defined on the basis of maximum number of iterations, i.e. 1000. The model convergence showed that the FDMPSO model was found to have converged after 674, 762, and 792 iterations for the set of four, five, and six wells, respectively, whereas the AEM-PSO model converged after 789, 841, and 876 iterations for the set of four, five, and six wells, respectively. Figure 7 shows the convergence of the AEM-PSO and FDMPSO models. The results show that the FDM-PSO model converged with less iteration than the AEM-PSO model. It was found that identifying the optimal location of wells increased the number of iterations for convergence of the model.

As AEM works on potential theory, groundwater head in the domain is calculated by adding the potential from all elements. Some modifications were made to the AEM model to take advantage of potential theory. In the AEM, hydrogeological elements are defined by unknown and known elements (Strack, 1989). Therefore, potentials from all known elements, i.e. river and recharge, and unknown elements, i.e. wells, were stored in separate matrixes. Then, the stored matrixes were used to find the unknown values of elements and generate the potential through each element and the corresponding groundwater head values for the whole domain (or at specific points only). Therefore, the potential for known elements was not calculated for each run of the simulation-optimization model. The benefit of this modification is to save time by exploiting the advantage of the potential theory approach, arriving at the final solution by adding the potentials of each individual element. As the potential for known elements are calculated once, computational time does not increase even if the model area is increased and more known elements are used. With FDM, the model area can be increased by creating more grids for that part which can increase the computational time, whereby the whole model needs to be rebuilt. Another advantage of the AEM, to give the groundwater head at a desired point without solving the whole domain, was also examined. In the optimization process, when the groundwater model was used to establish the groundwater head on the periphery of the wells, it was found that this advantage had a very efficient effect on computation time. After applying these modifications, the AEM model took less than $5 \mathrm{~s}$ to calculate the groundwater head, on the periphery of wells, for a single run of the model.

Sensitivity analysis was carried out for the piping length. Sensitivity of the models with respect to piping cost was examined by changing the per meter pipe length cost, using 100, 140, and 180 euros. The results show that a decrease in the cost of pipe length pushes the wells away from the reference location with a reduction in the value of the cost function. In this case, the pumping cost dominates which decreases with drawdown and hence the model tries to minimize the interference between wells by shifting the wells away from the reference location. On the other hand, an increase in the pipe length cost forces the wells to shift nearer to the reference location, leading to an overall increase in the value of the cost function. Sensitivity analysis was also carried out without considering the piping cost in the objective function. The analysis was made for the set of five wells which is the optimal number of wells for the study area. The result shows that the pumping wells shifted in the south part of the study area and close to the river side where the aquifer has more potential. Hence, it brings down the pumping cost, although it increases the length of pipes and the associated piping cost. This indicates that consideration of the piping cost in the objective function influences the location of the pumping wells hence the importance of including piping cost in the objective function. This analysis also validates the importance of AEM as it gives the exact location of pumping wells.

\section{SUMMARY AND CONCLUSIONS}

In this article, the advantages of using the AEM in a simulation-optimization approach were investigated. The AEM- and FDM-based simulation-optimization models were also compared. The AEM-PSO and FDM-PSO models developed were applied to hypothetical data and real field data. The models were applied to solve two kinds of management problems, i.e. maximum groundwater extraction from aquifer and minimum pumping cost for wells.

The AEM flow model was found to be efficient in solving groundwater management problems with some advantages over grid-based methods. Since the well coordinates were used as a decision variable, the optimal location of the wells was identified with both the AEM and FDM models. The results show that the AEM 
model gives the exact location of wells which helps establish a more realistic cost of piping compared with the FDM model. Also, as the groundwater head solution is continuous over the domain in the AEM model, it gives a more accurate drawdown near wells. This advantage helps establish a more realistic value for the cost function since the value of cost function is highly dependent on the value of drawdown. The ability of the AEM model to find the groundwater head directly at the required location, without solving the whole domain, saves computation time effectively. This benefit can be more significant for the larger sizes of domains. The study found that piping cost influences the locations of new wells and as a consequence, the value of the cost function. As it results, it should be considered in the objective function. This study also concluded that the PSO model is an efficient method and gives better results in comparison with linear programming and GA and HS. The results show that optimizing the location of wells using the AEM-PSO model increases the number of iterations for convergence of the model, whereas the FDM-PSO model converges with comparatively fewer iterations. In this study, highorder elements were not used. Computational efficiency can be increased further using these elements.

\section{NOTATIONS}

The following symbols have been used in this article.

$A_{1} \quad$ total cost for single well installation (euros)

$A_{2}$ total cost for the development per meter of pipe network (euros)

c any specific currency

$C_{\text {wi }} \quad$ well installation cost (euros)

$C_{\mathrm{pn}} \quad$ capitalized cost of pipelines (euros)

$C_{\mathrm{p}} \quad$ total cost of pumping (euros)

$C_{\mathrm{pE}} \quad$ capitalized electricity cost (pumping cost)

$C_{\mathrm{pu}} \quad$ cost of pump units (euros)

$G_{\mathrm{t}} \quad$ global best

$h_{i} \quad$ minimum water head on the periphery of the $i$ th well (m)

$H_{\mathrm{q}}$ aquifer thickness (m)

$H$ pumping head (m), equal to the head from the water table in the aquifer to the height of the storage tank

$k \quad$ hydraulic conductivity $(\mathrm{m} / \mathrm{s})$

$K \quad$ size of the swarm

$L_{i} \quad$ pipe length for $i^{\text {th }}$ well from reference location (m)

$N_{\text {w }} \quad$ total number of wells

$P \quad$ particles best

$P(h)$ penalty terms which vary linearly with the magnitude of constraint violation

$P(Q)$ penalty terms which vary linearly with the magnitude of constraint violation

$Q \quad$ discharge $\left(\mathrm{m}^{3} / \mathrm{s}\right)$

$Q_{i} \quad$ discharge $\left(\mathrm{m}^{3} / \mathrm{s}\right)$

$r \quad$ the rate of interest expressed (c/c/year)

$R_{\mathrm{E}} \quad$ the cost of the electricity per kilowatt-hour (c/kwh)

$V_{\max }$ maximum velocity limit $(\mathrm{m} / \mathrm{s})$
W complex discharge function

$\Psi \quad$ stream function $\left(\mathrm{m}^{3} / \mathrm{s}\right)$

$\Omega \quad$ groundwater flow $\left(\mathrm{m}^{3} / \mathrm{s}\right)$

$\phi \quad$ head (m)

$\beta_{1}, \beta_{2}$ weighting factors which can be selected according to the problem

$\Phi$ discharge potential $\left(\mathrm{m}^{3} / \mathrm{s}\right)$

$\omega$ inertia weight

$\chi \quad$ constriction coefficient

$\gamma \quad$ weight density of the fluid $\left(\mathrm{N} / \mathrm{m}^{3}\right)$

$\eta \quad$ combined efficiency of the pump and the prime mover

\section{REFERENCES}

Ahlfeld DP, Barlow PM, Mulligan AE. 2005. GWM-a ground-water management process for the U.S. Geological Survey modular groundwater model (MODFLOW 2000). U.S. Geological Survey Open-File Report.

Ahlfeld DP, Mulvey JM, Pinder GF. 1986. Designing optimal strategies for contaminated groundwater remediation. Advances in Water Resources 9: 72-84.

Ayvaz MT. 2009. Application of harmony search algorithm to the solution of groundwater management models. Advances in Water Resources 32: 916-924.

Bandilla KW, Jankovic I, Rabideau AJ. 2007. A new algorithm for analytic element modeling of large-scale groundwater flow. Advances in Water Resources 30: 446-454.

Cieniawski SE, Wayland J, Ranjithan S. 1995. Using genetic algorithms to solve multiobjective groundwater monitoring problem. Water Resources Research 31: 399-409.

Das A, Datta B. 2001. Application of optimization techniques in groundwater quantity and quality management. Sadhana: Academy Proceedings in Engineering Sciences 26: 293-316.

Dougherty DE, Marryott, RA. 1991. Optimal groundwater management. 1. Simulated annealing. Water Resources Research 27: 2493-2508.

Emch PG, Yeh WG. 1998. Management model for conjunctive use of coastal surface water and groundwater. Journal of Water Resources Planning and Management 124: 129-139.

Finney BA, Samsuhadi WR. 1992. Quasi-three-dimensional optimization model for Jakarta basin. Journal of Water Resources Planning and Management 118: 18-31.

Goldberg DE. 1989. Genetic Algorithms in Search, Optimization and Machine Learning. Addison-Wesley Publishing Company: Reading, MA.

Gorelick SM. 1983. A review of distributed parameter groundwater management modeling methods. Water Resources Research 19: 305-319.

Hunt RJ, Anderson MP, Kelson VA. 1998. Improving a complex finite difference ground water flow model through the use of an analytic element screening model. Ground Water 36: 1011-1017.

Jarboui BN, Damak P, Siarry A. 2008. A combinatorial particle swarm optimization for solving multi-mode resource-constrained project scheduling problems. Applied Mathematics and Computation 195: 299-308.

Johnson VM, Rogers LL. 1995. Location analysis in ground-water remediation using neural networks. Ground Water 33: 749-758.

Kennedy J, Eberhart R. 1995. Particle Swarm Optimization. Proceedings of the IEEE International Conference on Neural Networks (Perth, Australia). IEEE Service Center: Piscataway, NJ.

Kennedy J, Eberhart RC, Shi Y. 2001. Swarm Intelligence. Morgan Kaufman: San Francisco.

Lefkoff LJ, Gorelick SM. 1986. Design and cost analysis of rapid aquifer restoration systems using flow simulation and quadratic programming. Ground Water 24: 777-790.

Marryott RA, Dougherty DE, Stollar RL. 1993. Optimal groundwater management 2. Application of simulated annealing to a field-scale contamination site. Water Resources Research 29: 847-860.

Matott LS, Rabideau AJ, Craig, JR. 2006. Pump-and-treat optimization using analytic element models. Advances in Water Resources 29 760-775.

McKinney DC, Lin MD. 1993. Groundwater optimization using genetic algorithms. SIAM Conference on Computational Issues in the 
Geosciences. Society for Industrial and Applied Mathematics: Houston, TX.

McKinney DC, Lin MD. 1994. Genetic algorithm solution of groundwater management models. Water Resources Research 30: 1897-1906.

Moradi JM, Marino MA, Afshar A. 2003. Optimal design and operation of irrigation pumping station. Journal of Irrigation and Drainage Engineering 129: 149-154.

Olsthoorn TN. 1999. A comparative review of analytic and finite difference models used at the Amsterdam water supply. Journal of Hydrology 226: 139-143.

Qin XS, Huang GH, He L. 2009. Simulation and optimization technologies for petroleum waste management and remediation process control. Journal of Environmental Management 90: 54-76.

Ritzel BJ, Eheart JW, Ranjithan S. 1994. Using genetic algorithms to solve a multiple objective groundwater pollution containment problem. Water Resources Research 30: 1589-1603.

Rogers LL, Dowla FU. 1992. Groundwater remediation optimization with artificial neural networks and the genetic algorithm (abstract). Eos, Transactions, AGU, Fall Meeting 73: 186.

Shamir U, Bear J, Gamliel A. 1984. Optimal annual operation of a coastal aquifer. Water Resources Research 20: 435-444.

Sharma AK, Swamee PK. 2006. Cost considerations and general principles in the optimal design of water distribution systems. In ASCE Conference Proceeding 247: 85.

Strack ODL. 1989. Groundwater Mechanics. Prentice-Hall: Englewood Cliffs, NJ.
Swamee PK. 1996. Design of multistage pumping main. Journal of Transportation Engineering 122: 1-4.

Swamee PK, Sharma AK. 1990. Decomposition of large water distribution systems. Journal of Environmental Engineering 116: $269-283$.

Wang M, Zheng C. 1998. Ground water management optimization using genetic algorithms and simulated annealing: formulation and comparison. Journal of American Water Works Association 34: 519-530.

Wang QJ. 1991. The genetic algorithm and its application to calibrating conceptual rainfall runoff models. Water Resources Research 27: 2467-2471.

Wegley C, Eusuff M, Lansey K. 2000. Determining pump operations using particle swarm optimization. In Proceeding of Conference on Water Resources Engineering and Water Resources Planning \& Management, Minnesota.

Willis R, Finney BA. 1988. Planning model for optimal control of saltwater intrusion. Journal of Water Resources Planning and Management 114: 163-178.

Willis R, Yeh WWG. 1987. Groundwater Systems Planning and Management. Prentice-Hall: Englewood Cliffs, NJ.

Zheng C, Wang PP. 2002. A field demonstration of the simulation optimization approach for remediation system design. Ground Water 40: $258-266$. 